\title{
O legado da "Igreja dos pobres" para a Igreja na América Latina
}

\author{
The heredity of the "Church of the poor" for the Church \\ in the Latin America
}

Sueli da Cruz Pereira

\section{Resumo}

Na convocação para a realização do Concílio Vaticano II era evidente a necessidade da Igreja dialogar com o mundo atual e com todas as mudanças e transformações que ele acarreta. Como bem sabemos, cada participante do Concílio levava consigo as principais problemáticas e necessidades a serem refletidas a partir da realidade que o circunda. Neste sentido, se formaram dentro do Concílio alguns grupos de bispos que tinham a mesma visão social, política e eclesial para refletir as diversas temáticas. Dentre eles destacou-se o grupo "Igreja dos pobres". O próprio nome do grupo revelava o desejo de fazer com que o Concílio assumisse em seus documentos a centralidade dos pobres e a vivência de uma Igreja pobre e para os pobres. Este desejo não foi concretizado no Concílio, mas ficou com um legado para a Igreja na América Latina que assumirá a temática especialmente nas Conferências de Medellín e de Puebla, e em sua prática pastoral.

Palavras-chave: Concílio Vaticano II. Igreja dos pobres. Igreja latinoamericana.

\section{Abstract}

In the convocation to realize the Second Vatican Council it was evident the necessity that the Church has to dialogue with the present world and with all the changes and transformations that it entails. As we know well, each participant of the Council brought all the problems and necessities to be reflected starting from the reality which is around him. In this sense many 
groups of bishops who had the same social, political, ecclesial vision met together to reflect about the different themes. Among them stood out the group called "The Church of the poor". The name of the group reveled the wish to make the Council assumes, in their documents, the centrality of the poor and the living as a poor Church for the poor. This desire wasn't implemented in the Council, but it was one great heredity for the American Latin Church, which will assume the thematic especially in Medellín and in Puebla Conferences, and in their pastoral practices.

Keywords: Second Vatican Council. The Church of the poor. Latin American Church.

\section{Introdução}

O Concílio Vaticano II se desenvolve no seguinte contexto histórico: mudanças sociais e culturais do pós-guerra; presença ativa e crescente do Terceiro Mundo; industrialização dos países norte-atlânticos e as consequências de emigração, turismo, urbanizações gigantescas; transformações no mundo rural; nascimento da sociedade de consumo; emergência da televisão, com forte impacto na cultura e nos comportamentos; contexto teológico-pastoral; emergência das teologias da história e transcendental; desenvolvimento dos movimentos litúrgico e bíblico; retorno às fontes patrísticas e aparecimento da Ação Católica. ${ }^{1}$ Devido a esses fatores era necessária uma reflexão que correspondesse ao contexto histórico, como corajosamente propôs João XXIII ao convocar um Concílio que promovesse um aggiornamento da Igreja.

Diante de toda a problemática que a Igreja precisava encarar, encontravase a questão da pobreza presente nos diversos continentes. Dentro do Concílio nasce o grupo "Igreja dos pobres", que defenderá a causa dos pobres numa Igreja em processo kenótico para manter sua fidelidade ao Evangelho. Esse grupo será de grande importância no Concílio por visibilizar o mundo dos pobres dentro do mundo moderno. Os bispos conciliares latino-americanos trazem a herança experiencial e teórica do grupo "Igreja dos pobres" para a Igreja na América Latina.

${ }^{1}$ BOMBONATTO, V. I.; GONÇALVES. P. S. L. (Orgs.)., Concílio Vaticano II, p. 9. 
O legado da "Igreja dos pobres" contribuiu para uma eclesiogênese na América Latina onde a opção pelos pobres se faz eixo estruturante. Propomonos aqui apresentar em breves linhas como foi a recepção deste legado na Igreja latino-americana e sua importância nas Conferências Gerais do Episcopado Latino-americano, no nascimento das Comunidades Eclesiais de base e da Teologia da Libertação. E por fim ressaltaremos uma das consequências da opção pelos pobres: a perseguição e o martírio.

\section{A "Igreja dos pobres": o sonho de João XXIII}

Muitos temas importantes tratados no Concílio foram diluídos em seus documentos, dentre eles destacamos a relação da Igreja com os pobres. O tema estava no coração de João XXIII ${ }^{2}$ e sua vontade era que o tema dos pobres e da Igreja pobre fosse o eixo da constituição sobre a Igreja, o que não aconteceu. ${ }^{3}$ Um mês antes da abertura do Concílio, no dia 11 de setembro de 1962, em sua radiomensagem, o Papa falava da expectativa do início do Concílio e de elementos essenciais como a relação da Igreja e o Reino de Deus, Cristo como luz para a Igreja e para a humanidade, justiça e paz, dentre outros, e no tópico sobre a missão da Igreja a serviço da humanidade, surpreendendo a todos, lança o tema da "Igreja dos pobres": "Outro ponto luminoso. Em face aos países subdesenvolvidos, a Igreja se apresenta como é, e como quer ser, como a Igreja de todos, e particularmente dos pobres". ${ }^{4}$

Quando o Papa convocou o Concílio, a Igreja encontrava-se em uma zona de conforto e sem dialogar com o mundo moderno e seus avanços em todos os âmbitos. Fazia-se necessária uma volta às fontes, principalmente neotestamentárias e patrísticas, para ir ao essencial da missão da Igreja e para ter a capacidade de dialogar com este mundo, pois nele encontra-se inserida. Muitas eram as mudanças e atualizações que o Concílio precisava promover na Igreja. Devido a essa grande urgência alguns assuntos foram inseridos num tema maior, e isto aconteceu com o tema da "Igreja dos pobres".

\footnotetext{
2 "Ele próprio nunca escondeu sua origem humilde; ao contrário, sempre manteve os costumes simples, herdados de sua família camponesa italiana. Isto ele escreveu numa carta à sua mãe, irmãos e irmãs em Istambul, em 29 de julho de 1935: 'Sabeis que uma das maiores consolações de minha vida é minha família, que eu sempre elogio diante de todos: pobre, simples, humilde, mas boa e temente a Deus"”. DOMEZI, M. C., O Concílio Vaticano II e os pobres, p. 24.

${ }^{3}$ DOMEZI, M. C., O Concílio Vaticano II e os pobres, p. 25.

${ }^{4}$ JOÃO XXIII, PP., Radiomessaggio del Santo Padre Giovanni XXIII ai fedeli di tutto il mondo, a un mese dal Concilio ecumenico Vaticano II.
} 
A busca da unidade na diversidade de pensamentos dos membros do Concílio foi um grande desafio. Alguns bispos se uniram por afinidades de posições e formaram redes não oficiais durante o Concílio. Podemos citar as redes "Coetus Internationalis Patrum", "Ecumênico", "Opus Angeli" e "Igreja dos pobres". A Coetus Internationalis Patrum estava sob o comando de Monsenhor Marcel Lefebvre e contava com os brasileiros que tinham o apoio logístico da TFP (Tradição, Família e Propriedade): Dom Geraldo de Proença Sigaud, arcebispo de Diamantina e Dom Antônio de Castro Mayer, bispo de Campos (RJ). Esta rede radicalizou suas posições diante das propostas de atualização da Igreja que o Concílio propunha. No "Ecumênico" destaca-se a participação do Cardeal Malines, de Bruxelas, e do Cardeal Suenes, que era um dos moderadores do Concílio. Esta rede também teve uma intensa participação do episcopado brasileiro. A rede Opus Angeli nasceu por iniciativa dos bispos latino-americanos Hélder Câmara (Brasil) e Manuel Larraín (Chile) e do padre belga François Houtart. O grupo contava com os melhores peritos e teólogos empenhados na renovação. A rede "Igreja dos pobres" nasceu na primeira sessão do Concílio. O início foi marcado pelo padre francês Paul Gauthier, que trabalhava como padre operário em Nazaré (Galileia) e fundara a Fraternidade dos Companheiros e Companheiras de Jesus Carpinteiro. Estimulado por Hakim, arcebispo melquita de Nazaré, apresentou seu livro (que foi posteriormente publicado) Jesus, a Igreja e os pobres e conseguiu sensibilizar um grupo grande de bispos e peritos, dentre eles o padre Yves Congar, que escrevera o texto Pour une Église servante et pauvre (Por uma Igreja servidora e pobre) como proposta eclesial. ${ }^{5}$ No início o grupo maior era de vinte bispos da América Latina, dos quais nove eram do Brasil. O grupo todo teve a participação de 86 padres conciliares e contou com a presença de vozes influentes no Concílio como a de um dos quatro moderadores Cardeal Giacomo Lercaro, arcebispo de Bolonha, e de expressivas lideranças como D. Hélder Câmara (Brasil) e Manuel Larraín (Chile). Contou também com a participação de algumas mulheres como Marie-Therése Lescase (religiosa carmelita egressa que fora viver pobremente em Nazaré) e Aglaia Peixoto (Brasil). O objetivo do grupo era fazer com que o problema da evangelização dos pobres e do apostolado no meio operário tivesse centralidade no Concílio. ${ }^{6}$

O grupo "Igreja dos pobres" foi de fundamental importância para o Concílio. Mesmo não sendo reconhecido como oficial e não tendo conseguido

${ }^{5}$ BEOZZO, J. O., Presença e atuação dos Bispos brasileiros no Vaticano II, p. 147-148.

${ }^{6}$ DOMEZI, M. C., O Concílio Vaticano II e os pobres, p. 26-30. 
um de seus objetivos, o de formar no Concílio um Secretariado oficialmente dedicado à pobreza, a rede conseguiu atuar às margens da redação dos esquemas e textos conciliares fazendo que os temas do apostolado dos pobres e da pobreza da Igreja estivessem inseridos nos documentos oficiais. ${ }^{7}$ Apesar da divergência de visões sobre a pobreza, o grupo se manteve unido. Cada um via a pobreza de acordo com a realidade na qual estava inserido. Um dos segmentos do grupo era formado por praticantes da espiritualidade de Charles de Foucauld, na qual a centralidade era o escondimento e o completo abandono de si mesmo nas mãos de Deus ao serviço dos mais pobres e humildes. Refletiase mais a partir de uma perspectiva pastoral, onde a pastoral operária pudesse ser repensada para a atuação no meio dos pobres. Também havia um segmento mais dedicado à doutrina e à política. Outro segmento, que tinha D. Hélder Câmara como maior liderança, era o dos terceiro-mundistas, que viam a pobreza como fruto da injustiça; por isso denunciavam as causas do subdesenvolvimento e queriam o desenvolvimento a partir de uma ética cristã. Os pobres eram vistos como sujeitos e a Igreja deveria acompanhá-los em suas lutas de libertação.

O grupo propôs várias iniciativas como a criação do Secretariado da Pobreza, que, como já dissemos, não se realizou e teve propostas divergentes: uma mais prática, como realizar atos simbólicos em prol dos pobres; e outra mais teórica, onde se pudesse refletir teologicamente sobre a noção de pobreza.

Antes do término do Concílio o grupo selou um pacto que ficou conhecido como Pacto das Catacumbas. "O grupo mais permanente de 39 bispos, numa concelebração discreta na Catacumba de Santa Domitila, em 16 de novembro de 1965, selou um compromisso com a pobreza e o serviço aos pobres. Este compromisso recolheu a assinatura de mais de 500 padres conciliares". ${ }^{9}$ O Pacto contém treze proposições que comprometem viver a pobreza segundo o Evangelho: viver de acordo com o modo como a população vive no que se refere à habitação, alimentação etc.; renúncia aos trajes e insígnias de matéria preciosa; confiar a gestão financeira e material da diocese aos leigos; renúncia a imóveis e bens; renúncia a títulos que signifiquem grandeza e poder (pois preferem ser chamados de Padre); renúncia a privilégios, prioridades ou preferências; dar o tempo necessário para o serviço apostólico e pastoral das pessoas e grupos laboriosos e economicamente fracos e

\footnotetext{
${ }^{7}$ DOMEZI, M. C., O Concílio Vaticano II e os pobres, p. 29.

${ }^{8} \mathrm{O}$ texto do Pacto das Catacumbas encontra-se em KLOPPENBURG, B., Concílio Vaticano II, p. 526-528 e também em DOMEZI, M. C., O Concílio Vaticano II e os pobres, p. 105-107.

${ }^{9}$ BEOZZO, J. O., O Concílio Vaticano II e os pobres, p. 149.
} 
subdesenvolvidos; transformar as obras de beneficência em obras sociais baseadas na caridade e na justiça; cobrança aos governos através de obras para que decidam e ponham em prática as leis, as estruturas e as instituições sociais necessárias à justiça, à igualdade e ao desenvolvimento harmônico e total do homem todo; participar de investimentos urgentes dos episcopados das nações pobres e requerer junto aos organismos internacionais a adoção de estruturas econômicas e culturais que não fabriquem nações proletárias num mundo cada vez mais rico; partilhar a vida como irmãos em Cristo.

O tema da "Igreja dos pobres" não foi título de nenhum documento específico no Concílio, apesar de todos os esforços. Com a ajuda do moderador Lercaro e do grupo conseguiram inseri-lo nos documentos principais. A contribuição de Lercaro foi a de dissertar sobre o mistério de Cristo nos pobres e a presença de Cristo na Igreja. A partir desse fundamento cristológico, que reporta à origem da Igreja, o Concílio assume na Lumem Gentium, ${ }^{10}$ na $\mathrm{Ad}$ Gentes $^{11}$ e principalmente na Gaudium et Spes ${ }^{12}$ alguns parágrafos para o tema da pobreza. O tema também aparece em menor proporção em outros documentos. O desejo do Papa João XXIII de uma "Igreja dos pobres" não se realizara totalmente no Concílio.

\section{Da "Igreja dos pobres" à opção pelos pobres na América Latina}

O grupo "Igreja dos pobres" não alcançou o que esperava do Concílio, pois a questão da pobreza e dos pobres não estava no horizonte da maioria como sonhara João XXIII. Os bispos latino-americanos participantes do grupo empenharam-se para que na América Latina a "Igreja dos pobres" fosse a principal questão. No término do Concílio, ainda em Roma, juntamente com D. Manuel Larraín, presidente do Conselho Episcopal Latino-americano (CELAM) os bispos solicitaram a realização da II Conferência Geral do Episcopado Latino-americano. ${ }^{13}$ Os bispos sentiram a necessidade de reunir a Igreja da América Latina para que as decisões do Concílio fossem concretizadas à luz das novas situações sociais, econômicas e religiosas do Continente.

\footnotetext{
${ }^{10}$ LG 8.

${ }^{11}$ AG $5 ; 12$.

${ }^{12}$ GS $9 ; 63 ; 71 ; 72 ; 88$.

13 "A América Latina era o único continente que, ao chegar ao Concílio, já contava com uma estrutura episcopal de caráter colegial, o Conselho Episcopal Latino-americano, o CELAM, fundado no Rio de Janeiro (RJ), em 1955”. BEOZZO, J. O., Medellín.
} 
A realidade do Continente latino-americano na década de 60, caracterizada de um lado por miséria, opressão, dependência econômica, política e cultural e de outro lado por um desejo de mudança, de transformação, questionou a Igreja sobre sua atuação e presença nessa mesma realidade. A América Latina percebe que não é pobre, mas empobrecida, e por isso faz-se necessário libertar-se da dependência dos países de Primeiro Mundo. Vive-se, então, anos de uma dura repressão militar que terá uma repercussão importante na reflexão teológica e eclesial. É essa dura realidade terceiro-mundista que está presente no coração dos bispos latino-americanos participantes do grupo "Igreja dos pobres".

Nesse contexto destacamos alguns acontecimentos interligados que contribuíram para que a "Igreja dos pobres" se tornasse realidade neste chão latino-americano: a realização das Conferências episcopais latino-americanas, o nascimento da Teologia da Libertação, a inserção da Vida Religiosa nos meios populares e o nascimento das Comunidades Eclesiais de Base (CEBs).

A Conferência episcopal que acontece imediatamente após o Concílio foi realizada em Medellín, na Colômbia, no período de 24 de agosto a 6 de setembro de 1968. O tema da Conferência decidido em 1967 foi "A Igreja na atual transformação da América Latina à luz do Concílio". Destaca-se na Conferência de Medellín a influência de D. Hélder Câmara, arcebispo de Recife. Com Medellín inicia para a Igreja da América Latina um novo período na história do Continente latino-americano como afirmou o Papa Paulo VI no discurso de abertura da Conferência. O Concílio Vaticano II abre-se ao mundo moderno e Medellín destaca dentro do mundo moderno o "mundo dos pobres".

Em Medellín, ao contrário do Vaticano II, os bispos que fracassaram no seu intento de colocar os pobres no centro das preocupações da Igreja, lograram plenamente o seu objetivo. Os demais temas eclesiológicos, por mais relevantes que fossem, são deixados de lado em favor deste único que se transforma no documento 14, "Pobreza da Igreja". ${ }^{14}$

Retomando as orientações Conciliares, a Conferência de Medellín mergulha nos grandes desafios presentes no Continente. Para uma atuação mais eficaz da Igreja nessa sociedade fortemente marcada pela injustiça social, Medellín acentua o papel dos leigos na missão da Igreja no mundo. Os leigos são reconhecidos como sujeitos eclesiais de fundamental importância. A situação de pobreza convoca os cristãos para um compromisso com a causa dos

${ }^{14}$ BEOZZO, J. O., Medellín. 
pobres a fim de que aconteça a justiça social. Um segundo aspecto é que a pobreza passa a ser vista como um problema social que tem suas raízes na injustiça; por isso o assistencialismo e a esmola não resolverão uma questão que é estrutural. Além disso, os pobres passam de objetos a protagonistas de seu processo de libertação.

Medellín assume o vocabulário de libertação e abre as portas para uma nova reflexão. A reflexão teológica que aqui nasce concomitante a Medellín recebe dele o impulso para seu desenvolvimento. A realidade da América Latina não era a mesma europeia, pois aqui a questão da pobreza era emergente. Surge então uma teologia a partir do "seu próprio poço", ${ }^{15}$ cunhada como Teologia da Libertação, que inclui em seu interior a situação histórica e a realidade social dos pobres latino-americanos. "Caracterizar a América Latina como um Continente dominado e oprimido leva, naturalmente, a falar de libertação e, sobretudo, a participar no processo que ela conduz. De fato, tratase de um termo que exprime nova posição do homem latino-americano". ${ }^{16}$

A Teologia da Libertação compreende dois momentos distintos e complementares: formação e consolidação. O primeiro momento corresponde às décadas de 60 e 70 e o segundo, de 80 e $90 .{ }^{17}$ Alguns teólogos se destacam pela abordagem da temática dos pobres, tais como Gustavo Gutiérrez, Leonardo Boff, Jon Sobrino, o biblista Carlos Mesters entre outros. Sobrino chega a afirmar que "fora dos pobres não há salvação".

Uma das marcas que ajudaram a consolidar a Teologia da Libertação foi a III Conferência realizada em Puebla em 1979. Percutiam grandes tensões sobre a evangelização na América Latina. Uns achavam que a maior preocupação era o problema da secularização e do ateísmo moderno, e outros, a forma e a situação de miséria do povo pobre. Puebla assume a segunda visão fazendo uma "opção preferencial pelos pobres". As conclusões de Puebla intitulam-se: "Evangelização no presente e no futuro da América Latina".

O método adotado foi o ver-julgar-agir para o tratamento dos temas e do conjunto do documento. Sublinha-se em diversos parágrafos do documento a dimensão social e política da fé. Nesse contexto nascem várias Comunidades Eclesiais de Base (CEBs) e a Igreja latino-americana assume os traços de uma

\footnotetext{
15 Título do livro de Gustavo Gutierrez "Beber em seu próprio poço".

${ }^{16}$ GUTIÉRREZ, G., Teologia da Libertação, p. 83.

17 GONÇALVES, P. S. L., A teologia do Concílio Vaticano II e suas consequências na emergência da Teologia da Libertação, p. 86-87. Para um aprofundamento sobre as fases da Teologia da libertação sugerimos ANDRADE, P. F. C., Fé e eficácia.
} 
"Igreja dos pobres", partindo da situação do povo, de sua cultura, interesses e problemas.

As CEBs nasceram antes de Medellín, mas sua efervescência se dá na década de 70. Elas representam um novo jeito de ser Igreja. Os pobres se identificavam com esse jeito de ser Igreja e são a maioria nessas comunidades. A leitura da Bíblia, as orações, os cantos, eram uma forma de alimentar a esperança e lutar por sua libertação.

A partir das CEBs surgiram vários movimentos populares que lutavam por melhores condições de vida, reforma agrária, liberdade de associação sindical etc. Muitos religiosos e religiosas iniciaram uma Vida Religiosa inserida em meios populares antes de Medellín e contribuíram para o nascimento das CEBs e das lutas populares. Muitos bispos e padres também colocaram em prática o Pacto das Catacumbas vivendo inteiramente como pobres, com os pobres e para os pobres.

As Conferências do Episcopado Latino-americano de Santo Domingo (1992) e de Aparecida (2007), posteriores a Puebla, reafirmam a opção pelos pobres, mas não mais como tema estruturante, linha mestra, como o foi em Medellín e Puebla.

As afirmações sobre Cristo influenciaram poderosamente no sentido de forjar pastoralmente uma nova imagem dele, fazendo surgir o que se denominou Cristologia latino-americana ou Cristologia da libertação. Ressaltase a presença de Cristo na história e a presença de Cristo nos pobres. ${ }^{18}$ Essa base teológica sustenta a opção pelos pobres que a Igreja na América Latina consolida a partir de Medellín.

Medellín procurou fundamentar no exemplo de Cristo o seu vigoroso chamamento ao testemunho de pobreza e à reflexão que o acompanhava. E Puebla também recorre a esse fundamento cristológico. Nessa ótica, o eixo encontra-se na identificação com o Cristo pobre, conforme Mt 25,31-46, texto evangélico de grande relevância em Puebla e nos discursos do Papa no México. E também, como se sabe, um texto central nas comunidades cristãs de base e na reflexão sobre o compromisso libertador na América Latina. ${ }^{19}$

A opção pelos pobres na Igreja latino-americana é uma opção evangélica. Significa que é preciso seguir os passos de Jesus. A opção pelos pobres é para

\footnotetext{
${ }^{18}$ SOBRINO, J., Jesus na América Latina, p.18.

${ }^{19}$ GUTIÉRREZ, G., A força histórica dos pobres, p. 216.
} 
a Igreja uma missão que nasce da missão de Cristo, que se fez pobre por nós e manifesta a sua misericórdia preferencialmente aos pobres. A missão da Igreja nasce da missão de Cristo. Todo cristão é chamado a ter os mesmos sentimentos de Jesus $(\mathrm{F} 12,5)$ e por isso a opção pelos pobres não é uma escolha, é intrínseca à sua missão como continuador da missão de Cristo.

Atualmente falar de pobre e de pobreza parece causar certo desconforto na vida eclesial. Quando se afirma que a Igreja precisa fazer opção pelos pobres, a primeira pergunta é: “quem é o pobre?”. Jesus em sua misericórdia e compaixão nos mostrou o rosto dos pobres. Eram todos aqueles que viviam situações de exclusão e injustiça, não tendo assim o necessário para viver, mas que confiavam na ação de Deus. Sem "espiritualizar" a pobreza devemos ter sempre presente aqueles que vivem situações de miséria e de opressão causadas por um sistema que mata inocentes, assim como matou Jesus.

Nos pobres vemos o corpo de Cristo crucificado. Por isso o teólogo Jon Sobrino insiste em chamar os pobres presentes na América Latina de "povos crucificados", pois eles são o corpo de Cristo crucificado na história. Para se falar dos países pobres utilizamos mais os termos subdesenvolvidos, Terceiro Mundo, o Sul etc. Estas expressões não comunicam todo o mal que há no mundo. Afirma Sobrino: “existem, pois, povos crucificados. É necessário e urgente ver nosso mundo assim. E é bom chamá-los assim, porque com esta linguagem se acentua sua tragédia histórica e seu significado para a fé" ${ }^{20}$

As Conferências tiveram a convicção de que a opção pelos pobres está implícita na fé cristológica. Seguindo essa linha o Documento de Aparecida afirma:

sendo que esta opção está implícita na fé cristológica, os cristãos, como discípulos e missionários, são chamados a contemplar, nos rostos sofredores de seus irmãos, o rosto de Cristo que nos chama a servi-lo: "Os rostos sofredores dos pobres são rostos sofredores de Cristo". Eles desafiam o núcleo do trabalho da Igreja, da pastoral e de nossas atitudes cristãs. Tudo o que tenha relação com Cristo tem relação com os pobres e tudo o que está relacionado com os pobres clama com Jesus Cristo: "Tudo quanto vocês fizerem a um destes meus irmãos menores, o fizeram a mim" (Mt 25,40). ${ }^{21}$

${ }^{20}$ SOBRINO, J., O principio misericórdia, p. 86.

${ }^{21}$ DAp 393. 
A continuidade da opção de Jesus pelos pobres e excluídos é realizada a partir da ação concreta que move cada cristão a ir ao encontro do outro. É uma opção que tem suas raízes no amor de Deus manifestado através de Cristo. Em cada gesto de solidariedade e misericórdia concretiza-se o Reino. A opção pelos pobres faz da Igreja a "voz dos que não têm voz".

\section{Perseguição e martírio pela "causa de Jesus": a causa dos pobres}

Como consequência da opção pelos pobres a América Latina foi marcada pelo sangue derramado de muitos cristãos e cristãs que a partir de sua fé em Cristo se tornaram a "voz dos que não têm voz". A evangélica e corajosa opção pelos pobres, presente nos documentos das Conferências do Episcopado Latino-americano, refletiu-se na vivência de diversos cristãos para que a vida dos pobres, os crucificados da história, fosse respeitada, valorizada e dignificada. Muitos desses cristãos foram perseguidos e até martirizados por serem uma ameaça para o poder explorador. Estes martírios contribuíram para visibilizar a situação de miséria e de exploração em que viviam o povo. Esta solidariedade é um sinal de esperança, pois os pobres têm um motivo para acreditar que podem experimentar um futuro melhor e assim não desistir da vida. "É uma verdade cristã que ali onde há morte como a de Jesus, por defender as vítimas deste mundo, e com um grande grito, ali também há ressurreição, uma palavra continua ressoando e os crucificados permanecem na história". ${ }^{22}$

O martírio é visto na concepção oficial da Igreja como o morrer para dar testemunho de Cristo. Nos primeiros séculos do cristianismo a perseguição aos cristãos tinha como motivação oficial a não aceitação do culto a outras divindades por parte do Império Romano. A morte gerada pela perseguição contra a fé cristã ficou caracterizada como in odium fidei (por ódio à fé) ${ }^{23} \mathrm{Os}$ assassinados em defesa da vida são chamados espontaneamente pelo povo de "mártires". O "martírio" na América Latina não foi ocasionado in odium fidei, mas por razões históricas, sociais, militares, políticas e econômicas. Muitos cristãos foram presos e torturados, outros assassinados pelas forças repressivas do poder político e econômico. "A defesa do direito dos pobres à vida, na América Latina de hoje, conduz facilmente ao sofrimento e até à morte. Esse resultado, aparentemente paradoxal, revela a dimensão das resistências que será

${ }^{22}$ SOBRINO, J., O princípio misericórdia, p. 251.

${ }^{23}$ TAVARES, S. S., O martírio cristão, p. 121-122. 
necessário vencer para mudar a situação de 'pobreza antievangélica' que impera no subcontinente". ${ }^{24}$

Para a América Latina, martírio tornou-se sinônimo de todo aquele que tem uma morte como a de Jesus. Remete à morte e ressurreição de Jesus. E estes mártires revelam a presença de Deus nas cruzes da história. Diante da vivência de cristãos que morreram pela mesma causa de Jesus, anunciando com a própria vida a presença e proximidade de Deus na história, cresce a esperança. Sobrino afirma que

todo este sangue martirial derramado em El Salvador e em toda a América Latina, longe de levar ao desânimo e ao desespero, infunde novo espírito de luta e nova esperança em nosso povo. Neste sentido, se não somos um "mundo novo" nem um "novo continente", somos sim, claramente e de maneira verificável - e não precisamente pelas pessoas de fora - um continente de esperança, o que é um sintoma sumamente interessante de uma futura novidade frente a outros continentes que não têm esperança e a única coisa que têm é medo. ${ }^{25}$

Como exemplo martirial temos D. Oscar Romero, que em sua santidade viveu para defender o Reino. Seu martírio não foi por odium fidei (ódio à fé), mas por odium iustitiae (ódio à justiça) e por odium misericordiae (ódio à misericórdia). Passa-se, assim, da concepção de morrer por Jesus ou por causa de Jesus para o morrer pela causa de Jesus. ${ }^{26}$ Politicamente mata-se o líder para reprimir o movimento popular e o apoio da Igreja. A perseguição é ao líder do Povo de Deus, que anuncia o Reino com palavras históricas. Sua morte fazse necessária para dispersar o povo.

Muitos cristãos foram perseguidos e assassinados na América latina por causa da defesa do Reino: "Sacerdotes, religiosos e religiosas, catequistas e delegados da Palavra e simples fieis cristãos que foram ameaçados, difamados, expulsos, encarcerados e torturados; os templos, residências privadas, oficinas tipográficas, livrarias, colégios, cúrias vasculhados, metralhados, dinamitados e saqueados...". ${ }^{27}$

A perseguição é sinal de fidelidade ao Evangelho. A perseguição é por causa do Reino. Os perseguidores são os responsáveis pela injustiça e pela

\footnotetext{
${ }^{24}$ GUTIÉRREZ, G., Beber em seu próprio poço, p. 141.

${ }^{25}$ SOBRINO, J., O princípio misericórdia, p. 131.

${ }^{26}$ SOBRINO, J., Nosso mundo, p. 17.

${ }^{27}$ SOBRINO, J., Espiritualidade da Libertação, p. 109.
} 
estrutura de pecado que impedem a realização do Reino. Os cristãos são perseguidos ao lutar pela realização do Reino que os perseguidores detêm.

Uma Igreja fiel aos impulsos do Vaticano II e, sobretudo, de Medellín não demorou a ser vista como uma ameaça aos interesses dos poderosos, porque: a) essa Igreja denunciou a injustiça estrutural e a violência institucionalizada e desmascarou - e deste modo deslegitimou religiosamente - os princípios econômicos, sociais e políticos vigentes; e b) essa Igreja defendeu as esperanças dos pobres em sua libertação e os defendeu e animou a organizarem-se para consegui-la. ${ }^{28}$

As CEBs sempre fizeram memória de seus mártires em suas celebrações. Essa memória está ligada ao memorial do Senhor que sustenta a caminhada rumo ao Reino definitivo. Seus cantos expressam que o sangue derramado não foi em vão e que há uma esperança.

O martírio não é algo que se busca, mas que pode vir como consequência para aqueles que assumem a causa de Jesus. Hoje a realidade do martírio não é mais tão evidente como no meado do século passado. Isso não significa que os cristãos deixaram de assumir a causa de Jesus. A Igreja continua a sua missão através de seus pastores, dos religiosos e de inúmeros cristãos presentes nas diversas pastorais e movimentos eclesiais e sociais que acreditam numa "Igreja pobre e para os pobres" ${ }^{\prime 2}$ e por isso se esvaziam doando a própria vida. Muitos ainda hoje sofrem perseguição e calúnias em sua missão.

O desejo do Papa João XXIII de uma "Igreja dos pobres" e também do Papa Francisco de uma Igreja pobre para os pobres demonstra que a esperança para os pobres continua presente. A Igreja se solidariza com o pobre a ponto de ser uma com ele.

\section{Conclusão}

O legado da "Igreja dos pobres" para a Igreja latino-americana continua vivo, presente na Igreja, povo de Deus. A opção pelos pobres não foi um modismo das décadas passadas, mas uma opção evangelicamente enraizada que não passa com o tempo.

Não estamos mais no momento auge da visibilização da atuação da "Igreja dos pobres" na América Latina, mas somos testemunhas de pequenas

\footnotetext{
${ }^{28}$ SOBRINO, J., Espiritualidade da Libertação, p. 109.

${ }^{29} \mathrm{EG} 198$.
} 
brasas que ainda fumegam: a resistência de inúmeras Comunidades Eclesiais de Base; a reflexão de teólogos da libertação muito pertinentes para a atualidade; a inserção dos religiosos "aonde ninguém quer ir"; a presença de pastores apaixonados pelo Reino; a presença do Papa Francisco, pobre, misericordiosa e próxima dos pobres.

Apesar das Comunidades eclesiais de base não terem mais o mesmo perfil do início, pois passaram por fases de consolidação, seus membros mantêm vivo o espírito inicial no qual a opção pelos pobres não é alegórica, mas estruturante. Apoiadas pela Igreja continuam a existir, pois não são apenas um novo jeito de ser Igreja, mas como afirma D. Pedro Casaldáliga, "um modo normal de toda a Igreja ser", um modelo que desafia a capacidade de mudanças na Igreja.

Para se manter viva a opção pelos pobres é importante que a Igreja latinoamericana não deixe morrer a memória do Pacto das Catacumbas e de todo o martírio vivido nesta terra em prol dos pobres. O Pacto foi uma volta às raízes do sentido de ser pastor desta Igreja e o martírio um testemunho de que ser seguidor de Cristo é viver pela sua causa. Para se viver como pobres, com os pobres e para os pobres, é preciso decisão e conhecimento da prática de Jesus. O Pacto e o martírio mostram que quem deseja ser seguidor de Jesus precisa conhecê-lo para agir como ele agiu assumindo as consequências de uma vida doada.

\section{Referências bibliográficas}

ANDRADE, P. F. C. Fé e eficácia. O uso da sociologia na teologia da libertação. São Paulo: Loyola, 1991.

BEOZZO, J. O. Medellín: inspirações e raízes. Disponível em: $<\mathrm{http} / / / \mathrm{www}$.servicioskoinonia.org/relat/202.htm>. Acesso em: $01 \mathrm{dez} .2015$.

BEOZZO, J. O. Presença e atuação dos Bispos brasileiros no Vaticano II. In: BOMBONATTO, V. I.; GONÇALVES. P. S. L. (Orgs.). Concílio Vaticano II. Análise e prospectivas. São Paulo: Paulinas, 2004. p. 117-162.

BOMBONATTO, V. I.; GONÇALVES, P. S. L. (Orgs.). Concílio Vaticano II. Análise e prospectivas. São Paulo: Paulinas: 2004.

CELAM. Discípulos e missionários de Jesus Cristo para que nele nossos povos tenham vida: conclusões da V Conferência Geral do Episcopado Latino-Americano: Aparecida, 2007. São Paulo: Paulus, 2008. 
CONCÍLIO VATICANO II. Constituição Dogmática Lumen Gentium. Compêndio do Vaticano II. Petrópolis: Vozes, 1968.

CONCÍlIO VATICANO II. Constituição Pastoral Gaudium et Spes. Compêndio do Vaticano II. Petrópolis: Vozes, 1968.

CONCÍLIO VATICANO II. Decreto Ad Gentes. Compêndio do Vaticano II. Petrópolis: Vozes, 1968.

DOMEZI, M. C. O Concílio Vaticano II e os pobres. São Paulo: Paulus, 2014. FRANCISCO, PP. Exortação Apostólica Evangelii Gaudium sobre o anúncio do Evangelho no mundo atual. São Paulo: Paulinas, 2013.

GONÇALVES, P. S. L. A teologia do Concílio Vaticano II e suas consequências na emergência da Teologia da Libertação. In: BOMBONATTO, V.I.; GONÇALVES. P. S. L. (Orgs). Concílio Vaticano II. Análise e prospectivas. São Paulo: Paulinas: 2004. p. 69-94.

GUTIÉRREZ, G. A força histórica dos pobres. Petrópolis: Vozes, 1984.

GUTIÉRREZ, G. Beber em seu próprio poço. Itinerário espiritual de um povo. São Paulo: Loyola, 2000.

GUTIÉRREZ, G. Teologia da Libertação: perspectivas. Petrópolis: Vozes, 1975.

JOÃO XXIII, PP. Radiomessaggio del Santo Padre Giovanni XXIII ai fedeli di tutto il mondo, a un mese dal Concilio ecumenico Vaticano II. Disponível em: $<\mathrm{https}$ ://w2.vatican.va/content/johnxxiii/it/messages/pont_messages/1962/doc uments/hf_jxxiii_mes_19620911_ecumenical-council.html $>$. Acesso em: 04 dez. 2015 .

KLOPPENBURG, B. Concílio Vaticano II. Petrópolis: Vozes, 1966. v.5.

SOBRINO, J. Espiritualidade da libertação. Estruturas e conteúdos. São Paulo: Ed. Loyola, 1992.

SOBRINO, J. Jesus na América Latina. São Paulo: Vozes / Loyola, 1985.

SOBRINO, J. Nosso mundo. Crueldade e compaixão. Concilium, n. 299, p.1221, jan./fev. 2003.

SOBRINO, J. O princípio misericórdia: descer da cruz os povos crucificados. Petrópolis: Vozes, 1994. 
TAVARES, S. S. O martírio cristão: expressão da misericórdia consequente. In: SOARES, A. M. L. (Org.). Dialogando com Jon Sobrino. São Paulo: Paulinas, 2009. p. 121-153.

Sueli da Cruz Pereira Doutoranda em Teologia pela Pontifícia Universidade Católica do Rio de Janeiro Rio de Janeiro / RJ - Brasil E-mail: irscruz@yahoo.com.br

Recebido em: $31 / 07 / 18$ Aprovado em: 30/10/18 